DOI: $10.25100 /$ pfilosofica.v0i53.11519

“HABLARÁS DE TI, PERO NO CONTARÁS SOBRE NOSOTROS". LA CONFESIÓN FOUCAULTIANA APLICADA EN LA DINÁMICA DE CONSULTA ENTRE EL POLICÍA NACIONAL PARAGUAYO Y LOS PSICÓLOGOS DE LA INSTITUCIÓN

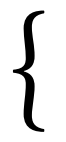
$\left.\begin{array}{r}\text { Carlos Aníbal Peris Castiglioni } \\ \text { Universidad Nacional de Asunción, Paraguay }\end{array}\right]$

\title{
Resumen
}

Teniendo en cuenta el concepto de Michel Foucault sobre la confesión, se ha analizado al agente de la Policía Nacional del Paraguay según lo mencionado por los psicólogos de la institución. ¿Cómo se ha dado el contexto de atención?, y ¿cuáles han sido las fundamentales causales de consulta?, aquellas preguntas se radicaron en las indagaciones guías por parte de cuatro terapeutas que se desempeñaron en un hospital especializado y en dos comisarías de la ciudad de Asunción. Con respecto a las principales conclusiones, el agente ha necesitado de una imperiosa contención y de un profundo cambio en sus formas de ser y modos de relacionarse con sus compañeros y con los externos a su profesión, población en general y allegados. La Policía Nacional Paraguaya no fue un grupo homogéneo, que solo se ha dedicado a acatar órdenes, ha gozado de una vivencia diaria, definida por sus prácticas que ha afectado a sus miembros y, en algunas ocasiones, la ha llevado a confesar sus dramas, con el fin de ser mejores personas, fundamentalmente en los contextos familiares; así, la confesión policial se entendería como una "técnica de si".

Palabras clave: confesión; seguridad; cuidado de sí; psicología; verdad.

Cómo citar este artículo: Peris Castiglioni, C. A. (2021). "Hablarás de ti, pero no contarás sobre nosotros". La confesión foucaultiana aplicada en la dinámica de consulta entre el policía nacional paraguayo y los psicólogos de la institución. Praxis Filosófica, (53), 183-204. https://doi.org/10.25100/ pfilosofica.v0i53.11519

Recibido: 7 de marzo de 2021. Aprobado: 29 de mayo de 2021 


\title{
"You will talk about yourself, but you will not tell about us." The Foucauldian confession applied in the consultation process between the Paraguayan national police and the psychologists of the institution.
}

\author{
Carlos Aníbal Peris Castiglioni ${ }^{1}$
}

\begin{abstract}
Considering Michel Foucault's concept of confession, the Paraguayan national police have been analyzed in accordance with what was mentioned to the institution's psychologists. How has the healthcare context been given? and, what were the main reasons for the consultation? The questions were posed in the guiding inquiries to four therapists who worked in a specialized hospital and in two police stations in the city of Asuncion. Regarding the main conclusions, the agent has needed an imperious restraint and a profound change in his forms and ways of relating to his colleagues and with those outside his profession, the general population and those close to him. The Paraguayan National Police has not been a homogeneous group that has only dedicated itself to following orders, it has enjoyed a daily experience, defined by its practices that has affected it and, on some occasions, has led it to confess its dramas with the end of being better people, fundamentally in family contexts: the police confession as "self-technical".
\end{abstract}

Keywords: Confession; Security; Self-care; Psychology; Truth.

\footnotetext{
${ }^{1}$ Sociólogo e investigador categorizado del CONACYT. Doctor en Ciencias Humanas y Sociales por la Universidad Nacional de Misiones. Investigador de la Universidad Nacional de Asunción. Director de la Carrera de Sociología, Historia y Ciencia Política de la Universidad Católica "Nuestra Señora de la Asunción". Líneas de investigación enmarcadas en el narcotráfico de frontera y prácticas de la Policía Nacional Paraguaya. Pasantía Doctoral en el Instituto Universitario de Lisboa. Profesor Visitante en la Universidad Nacional de Yokohama. Investigación en el GIGA de Hamburgo y en la Fundación InSight Crime.
}

ORCID: 0000-0002-8205-3768 E-mail: cperis@rec.una.py 


\section{“HABLARÁS DE TI, PERO NO CONTARÁS SOBRE NOSOTROS”. LA CONFESIÓN FOUCAULTIANA APLICADA EN LA DINÁMICA DE CONSULTA ENTRE EL POLICÍA NACIONAL PARAGUAYO Y LOS PSICÓLOGOS DE LA INSTITUCIÓN}

Carlos Aníbal Peris Castiglioni Universidad Nacional de Asunción, Paraguay

\section{Planteamiento: la confesión policial}

Inicialmente se expone que en Michel Foucault (1926-1984) el fenómeno de la seguridad ha sido un dispositivo (Foucault, 2008, p. 41). Esto, a su vez, se halló dirigido a un conjunto decididamente heterogéneo que comprendió discursos, instituciones, instalaciones arquitectónicas, decisiones reglamentarias, leyes, medidas administrativas, enunciados científicos, proposiciones filosóficas, morales y filantrópicas (Foucault, Dits et écrits, vol. III, p. 229, citado por Agamben, 2011, p. 250).; en resumen, elementos que pertenecieron tanto a "lo dicho" y a lo "no-dicho" (Garcia Fanlo, 2011, p. 1).

En el intelectual francés, las sociedades contemporáneas podrían ser admitidas en los términos de "sociedades de seguridad", unas que se erigieron con base a unos "dispositivos de seguridad" que se enmarcaron al gobierno del riesgo, del cálculo, pero, además, y en alternas palabras, a la regulación de la población en un territorio determinado (Torrano, 2016, p. 80). En tal sentido, entender a los dispositivos de seguridad, implicaría examinarlos dentro de la historia de la gubernamentalidad: más precisamente en el poder pensado en la lógica del gobierno de la conducta; en relaciones de poder estipuladas en regir y gestionar la vida de los otros y de sí mismo (Foucault, 2012, p. 98). 
En este panorama tomó preponderancia el dispositivo policial, con un rol asignado que permitiera cumplir con los propósitos de aquella clase de gubernamentalidad (Castro, 2019, p. 201). Los Estados modernos, a la premisa del gobierno con el fin de reglar los comportamientos, han buscado integrar a las diversas personas en su propia totalidad a través del dispositivo policial, lo cual actuaría bajo la racionalidad de lo establecido (Vélez Vega, 2016, p. 118). Expresado de otra manera: la policía fue esencialmente un dispositivo de acción para con la ciudadanía, constituyéndose, en el presente, con una función represiva y de auxiliar de la justicia (Castro, 2019, p. 202).

Los planteamientos anteriores, introductorios, pertinentes y válidos en sus interpretaciones, colocaron la atención en un nivel de análisis macroestructural (Castro-Gómez, 2007, p. 157). Aunque hayan sido oportunos, obviaron, sin embargo, la dimensión individual del dispositivo policial, fijada en la indagación de las fuerzas mediante la observación de sus miembros o de los oficiales que conformaron a la tropa. A lo trazado, emergió la pregunta intuitiva de la investigación: ¿cómo estudiar a los policías, $y$, en definitiva, al dispositivo desde adentro?

$\mathrm{Al}$ respecto, en la búsqueda de una herramienta de examinación al policía, se cita las consideraciones de Foucault sobre la confesión: el hombre en occidente ha llegado a ser un animal de confesión (Foucault, 2011, p. 58). En dicho acto el ser humano, y más aún el moderno, ha declarado sus apreciaciones morales, crímenes, pecados, violaciones a las leyes y aspiraciones (Romero, 2017, p. 10). Foucault afirmaba: Freud trasladó la confesión de la rígida retórica barroca de la iglesia al relajante diván del psicoanalista (Foucault, 2012, p. 132).

Concluyentemente en la actualidad, la confesión ha trascendido del ámbito religioso y judicial convirtiéndose en una adecuada forma de inspección del hombre contemporáneo: la confesión se da como una práctica que se halló en las áreas social, económica y psicológica/científica, principalmente (Romero, 2017, p. 11).

La confesión difundió hasta muy lejos sus efectos: en la justicia, en la medicina, en la pedagogía, en las relaciones familiares, en las relaciones amorosas, en el orden de lo más cotidiano, en los ritos más solemnes; se confiesan los crímenes, los pecados, los pensamientos y deseos, el pasado y los sueños, la infancia; se confiesan las enfermedades y las miserias; la gente se esfuerza en decir con la mayor exactitud lo más difícil de decir (Foucault, 2011, p. 56). 
Con los enunciados recién expuestos, el pensador de Poitiers concluía que, desde la ilustración, la confesión logró conquistar nuevos espacios, pero, e incluso, se pasó de la confesión fundada en la culpa: "el yo maté" a una confesión holística; ya no se indagaba únicamente en el crimen sino en la biografía del criminal, sus pasiones, su vida en general (Romero, 2017, p. 12). En resumen, la confesión no solo ha ganado una mayor aplicación en las diversas esferas de la cotidianeidad, además cambió en la manera de inquirir a otros aspectos de la existencia.

Además, el hecho de confesar necesariamente requirió un poder. En sus cursos El poder psiquiátrico (1973-1974) y Los Anormales (1974-1975), la confesión se unió directamente al ejercicio del poder: los locos hablaban sobre su delirio y aceptaban lo dicho por el médico siempre y cuando el agua, la silla o la ducha, estuvieran de por medio (Foucault, 2003, p. 67). A esta premisa, el poder psiquiátrico obtuvo la confesión de los internados, mediante prácticas estipuladas en el otorgamiento, o no, de comodidades y/o beneficios materiales. Por lo tanto, la confesión emergió con un papel fundamental en la relación poder-saber. El saber que circuló como poder y este procedió como saber, ambos munidos entre sí, no expresados de manera diferente o separados: "no hay poder que se ejerza al margen de un saber, no hay saber que no engendre a su vez poder" (Foucault, 2011, p. 60).

Ejecutando una breve suposición a priori, llevando lo complejizado al quehacer policiaco, correspondería al agente obtener las declaraciones de cualquier habitante, sospechado de trasgredir la norma pública. En alternativas palabras, fueron ellos los que gozaron de un poder de coacción, no solo por usar el arma, sino por las atribuciones fijadas, en la estructura estatal, de establecerse en aquellos, que solicitaron enunciados de justificación en virtud de una duda atribuida para con el ciudadano, una fundamentada por intentar transgredir el bienestar dictaminado en la idea tácita del contrato social fundacional (Moriconi, 2013, p. 24). Lo mencionado se relaciona consecuentemente con los dominios de la lógica del saber-poder foucaultiano.

Así, el policía es un ser de confesión, por sus propias facultades asignadas. La confesión aplicada por el agente fue una atribución heredada del poder pastoral (Castro, 2019, p. 203), un poder caracterizado por el establecimiento de una serie de reglas dirigidas en lograr la individualización por sujeción a partir de la extracción, lo más detallada posible, de la verdad interna de todos y cada uno (Valencia, 2014, p. 125). Es lo que se denominó en "Estado de policía": 
En el orden de lo que hoy llamaríamos política interna, ¿qué implica el Estado de policía? Pues bien, implica justamente un objetivo, o una serie de objetivos que podríamos calificar de ilimitados, en cuanto la cuestión, para quienes gobiernan ese Estado, pasa por tomar en cuenta, y hacerse cargo de la actividad no sólo de los grupos, no sólo de los diferentes estamentos, esto es, de los diferentes tipos de individuos con su estatus particular, sino de la actividad de las personas hasta en el más tenue de sus detalles. En los grandes tratados de policía de los siglos XVII y XVIII, todos los que cotejan los distintos reglamentos y tratan de sistematizarlos coinciden en esto, y lo dicen expresamente: el objeto de la policía es un objeto casi infinito" (Foucault, 2008b, p. 22).

Lo expuesto hasta el momento, unido con las aproximaciones de la confesión, realizadas por Foucault durante su etapa genealógica del saberpoder, se radicarían en pertinentes si se deseara considerar la actuación del gendarme para con la población: su rol de confesor. Es propósito de este tratado, sin embargo, analizar al policía, no a partir de dicho papel sino, y más bien, en una dinámica más particular, profunda e individual: la persona que oficia de policía, con sus motivaciones y problemas. Centrarse en tal tarea, significaría pasar al concepto de confesión enmarcado en los dominios de una práctica cuadrada, en la constitución de la subjetividad, expresada en las "tecnologías del yo" o "técnicas de sí".

A lo señalado, el problema de la confesión tomó un rumbo diferente en 1980, cuando Foucault dictó el curso: Sobre el comienzo de la hermenéutica de si (Romero, 2017, p. 13). Se problematizaba: creo que, si se quiere analizar la genealogía del sujeto en la civilización occidental, hay que tener en cuenta no solo las técnicas de dominación sino también las técnicas de sí (Foucault, 2008c, p. 147). En la etapa genealógica Foucault procuró examinar los procesos de normalización y vigilancia a través de las confesiones, una práctica que redimió y encasilló al individuo en sujeto culpable; por otra parte, en la subjetividad, fue el ser humano quien se constituyó a sí mismo en el centro de esta práctica.

Ante esta nueva consideración, la confesión ya no sería únicamente vista desde el binomio poder-saber, además se la consideraría en una tecnología: los hombres recurrieron para formar una verdad en aquello desde una técnica para apaciguar su preocupación de sí (Romero, 2017, p. 14). A lo estipulado, en consecuencia, se definió por "tecnologías del yo" o "técnicas de sí", en:

Técnicas que permiten a los individuos efectuar, por sus propios medios, un cierto número de operaciones sobre sus propios cuerpos, sobre sus propias almas, sobre sus pensamientos, sobre su conducta, y ello de tal modo que 
se transforman a sí mismos, se modifican, y alcanzan un cierto estado de perfección, de felicidad, o de pureza, de poder sobre natural, etc. (Foucault, 2008c, p. 148).

Para luego agregar, más específicamente, adecuando la confesión con la "técnica de sí":

Un acto verbal mediante el cual el sujeto plantea una afirmación sobre lo que él mismo es, se compromete con esa verdad, se pone en una relación de dependencia con respecto a otro y modifica a la vez la relación que tiene consigo mismo (Foucault, 2014, p. 33).

La confesión como "tecnología del yo" fue una forma mediante la cual el sujeto buscó una transformación de lo que fue: el individuo ha mencionado algo de lo que fue, y tal decir, salió hacia un interlocutor que lo escuchó, y bajo el cual se estuvo en una relación de dependencia. Así, fue el propio ser el que, por su cuenta misma, estableció ese vínculo: él fue quien buscó al cura, al psicoanalista, al otro ante quien sostuvo lo dicho (Romero, 2017, p. 14). De hecho, una verdad no bastaría con decirse; se necesitaría al otro que escuchara, la relación de dependencia, ya que, sin estos dos elementos, la verdad pronunciada no causaría inquietudes en quien la dijo.

El policía fue y es un ser humano, que pasó por experiencias personales y profesionales, las cuales marcaron su labor, generando un conjunto de discursos en los cuales se han conseguido valorar sus problemas, frustraciones, sueños, incertidumbres e inconvenientes. Aludiendo de una alterna manera: el policía además de ser un confesor, por su papel como regente de la sociedad, también se confesó, en tanto que ha buscado expresarse, sobre sí mismo y, ante ello, generar o construir una verdad sobre sí. En lo recién indicado, se encontró la motivación de la presente investigación en inquirir más precisamente al policía paraguayo en sus respectivas confesiones.

Ante ello, se ha apreciado que el primer mecanismo de contención interna en la entidad policial, en el Paraguay, se dio brindando asistencia psicológica a los oficiales, sea por las complicaciones surgidas en el desempeño de la tarea de protección, por los dramas personales de la vida familiar, por los inconvenientes éticos deliberados, o por el atosigamiento del compañero. Tal dinámica es la que interesó al artículo, seleccionándola como el recurso adecuado, con el fin de caracterizar al policía paraguayo, según lo que mencionaron a sus terapeutas. 
El policía paraguayo, a pesar de que en los principios normativos se lo estableció como un ente apolítico, ascético, desinteresado y moralmente correcto (Meza, 2010, p. 4), se radicó en una persona. Él ha vivido en una constante interacción, el de dar seguridad en las calles, comisarías y en sus casas, relacionándose con sus superiores, compañeros, ciudadanos en general y con los integrantes de sus propias familias. La tarea no fue solo instrumental, entraron en juego tensiones, aspiraciones, frustraciones, en definitiva, una actividad difícil y discontinua, que ocasionó un enorme desgaste físico, pero también uno anímico, muchos de ellos con aciagas consecuencias.

Vale recordar, el caso del cuádruple homicidio perpetrado por el suboficial Isidro Casco Salinas que, el 3 de julio del 2020, en una vivienda de Capiatá - Departamento Central, asesinó a sus dos hijos, suegros y cuñada, y posteriormente se suicidó. Su pareja, que se encontraba en España trabajando, declaró que el mismo se topaba muy presionado, con un alto estrés, exhibiendo indicios de alucinaciones y delirios de persecución (Diario La Nación, 2020 julio 3).

Luego del trágico evento, Alodia Garrigoza, jefa de la Sección de Selección y Admisión de la Policía Nacional, admitió que de los 6.000 agentes que anualmente piden promoción de cargo, 3.000 exteriorizaron algún trastorno síquico en los test aplicados (Diario ABC Color, 2020 julio 3). Franca Lacarruba, presidenta de la Sociedad Paraguaya de Psicología, recomendó evaluar el estado mental de los sujetos de protección por lo menos una vez al año, e instó a las autoridades estatales a contratar una mayor cantidad de terapeutas, con el fin de ampliar la oferta y dar más oportunidades de sanación al equipo.

A lo planteado teórica y coyunturalmente, el presente artículo se propuso caracterizar al gendarme paraguayo de una manera reflexiva, abierta e íntima. En resumen: estudiar a un individuo lejos de su clásica posición de confesor, ubicándolo en el lado de quienes lo contaron todo, aguardando un auxilio, para asentar su confesión como si se tratrara de una técnica de sí. Las preguntas guías fueron: ¿cómo se dio el contexto de atención? y ¿cuáles han sido las fundamentales causales de visita? Dichas indagaciones, a su vez, representaron los dos momentos que dieron la estructura expositiva a la investigación: el escenario y los inconvenientes.

Las dos cuestiones se constituyeron en el punto de indagación por parte de cuatro psicólogos que se desempeñaron dentro de la organización - dos de ellos en un hospital nacional especializado en el cuidado a policías $\mathrm{y}$, los restantes, en comisarías barriales de la ciudad de Asunción-. La metodología correspondió al enfoque cualitativo, con la aplicación de 
entrevistas a profundidad, realizadas entre diciembre del 2019 y enero del 2020. Por razones éticas de privacidad y resguardo del bienestar laboral, los profesionales recurridos han quedado bajo el anonimato. Los testimonios fueron transcriptos y presentados tal cual se expresaron por sus interlocutores.

\section{El escenario: el contacto de origen y las causas de consulta}

La pesquisa ha comenzado adentrándose en el contexto de atención. Las preguntas se orientaron hacia el entendimiento de cómo se ha dado el contacto de origen entre el especialista y el policía. Al fijar el interés en el "contacto de origen", el artículo ha intentado indagar en los sentimientos y dinámicas que surgieron en los agentes con un rol de pacientes, en definitiva: ¿se mostraron tensos?; ¿acudieron tranquilos al psicólogo?; ¿existieron presiones externas en ellos? Al respecto, el Entrevistado n. ${ }^{\circ} 1$, aquel que ha sabido llevar su función en una comisaría de la ciudad de Asunción, señalaba un entorno complejo, primordialmente por una carencia de infraestructura en la consulta:

No hay un espacio propicio. Mira arriba y observa que las piezas no son cerradas, una simple mampara divisoria que no consigue tocar el techo. Lo que uno cuenta acá, el resto, si se lo propone, lo podrá escuchar y no se provocará el secretismo. El que viene con nosotros lo hace con una actitud de recelo, teme que le estén oyendo y es ahí donde se ha ocasionado una ruptura, desde un principio, con lo que se quiere mencionar y con lo que te indicaron. Yo a esto lo denomino el efecto de incoherencia y resignación, la existencia entre el deseo y lo que se puede en verdad expresar (Entrevista n. ${ }^{\circ}$ 1. Comisaría de la ciudad de Asunción, 14/12/2019).

Lo recién enunciado fue verificado por el segundo requerido. A diferencia del anterior, el ahora recurrido no percibió una paga por sus servicios. Su trabajo en una de las dependencias fue de manera voluntaria. Afirmó que su práctica con los vigilantes, se debió a un compromiso autoimpuesto por la memoria de su padre que, y en sus palabras, era un "gran oficial, chapado a la antigua". Además del lugar, puso énfasis en la excesiva cautela e imperiosa valentía en los inicios de la terapia:

No es solo la ausencia de un despacho aislado, va más por el hecho que el que tiene el afán de venir debe caminar por ese pasillo y, al pasarlo, sus colegas empiezan a sospechar. ¿Por qué se va con él?, se murmura, pero ese susurro es lo suficientemente fuerte. Son muy pocos los que se atreven, se creó un ambiente complicado. Los que acuden, antes de estar relajados, se muestran intranquilos. A mí no me deja de sorprender, son personas que 
se les enseñó a disparar, a morir y matar, sin embargo, en el sillón sudan, se mueven, se rascan, les cuesta abrirse. Aquí no poseen el valor, parece ser (Entrevista n. ${ }^{\circ}$ 2. Comisaría de la ciudad de Asunción, 22/12/2019).

Lo recogido hasta el momento, ostentó una visible hostilidad para el interesado en la asistencia mental. Sea por la escasez de insumos, o una tácita presión por el "qué dirán", una materializada en el miedo al comentario exterior, el que ha visitado al psicólogo se encontró en una difícil situación, consigo mismo y con los otros. En este punto se han munido dos realidades cotidianas de la institución policial paraguaya: a) una económica: tangible en una insuficiente inversión orientada al crecimiento, promoción de nuevas actividades y al resguardo integral de las fuerzas; y b) una cultural: un sentimiento de recelo por la inseguridad aparecida en la figura y presencia de los pares.

Ejemplificando lo sentenciado en el párrafo antepuesto, vale recordar las declaraciones del senador Stephan Rasmussen, que luego del estudio ejecutado al Presupuesto General de la Nación del año 2019, lamentaba la nula importancia del sector dirigencial en dotar de una forma óptima al quehacer del protector de lo público, sea en el oficio acaecido en las calles, o en uno de prevención entorno a la salud física y psíquica del custodio (Diario La Nación, 2019 septiembre 24). Igualmente, se trae a colación el asesinato del oficial de investigaciones Fredy César Díaz que, en enero de 2021, fue aparentemente ultimado por uno de sus compañeros de filas tras un confuso episodio de tráfico de drogas y liberación del capo mafioso Teófilo "Samura" Samudio (Diario ABC Color, 2021 enero 25). El suceso adquirió una magna trascendencia, incluso el jefe zonal, Rubén Paredes, recalcó que ha existido un sistema de ajusticiamiento paralelo entre los policías que no compartieron ciertos valores, códigos y comportamientos.

Profundizando, gracias a las primeras dos intervenciones, emergió un aspecto fundamental a considerar: el daño que se ocasionó por los dichos de los colegas. El tercer indagado, que se desempeñó en un hospital nacional, reflexionaba en la construcción de una gran red de habladurías, una repleta de mentiras y prejuicios que posicionaron al paciente en un ser débil, uno no apto:

En Paraguay de por sí luego se piensa que si venís acá es porque estás loco, no es la excepción tampoco en tal caso. Aquí va por el mostrarse frágil. Como se sabe todo, tarde o temprano se tiran la primicia que alguien pisó la oficina y ahí se origina el chismerío, uno que se agranda a cada momento. Ves que no fue por una cuestión del lugar únicamente, aquello siempre se 
lograría conseguir o improvisar, va por la filtración que se llegó a nosotros y que uno se exhibió, posteriormente, de una forma blanda. El tema es más complicado ya que además de la imagen de sensibles empiezan las incertidumbres, si se estuviera diciendo algo malo: ¿qué será que le pasa a fulanito?; ¿qué le dijo?; o ¿seguro que él no se halla bien? (Entrevista n. ${ }^{\circ} 3$. Hospital de la ciudad de Asunción, 27/01/2020)

El Entrevistado n. ${ }^{\circ}$ 4, profesional con casi un lustro en la policlínica ya aludida, concordaba con las afirmaciones antes vertidas. Él, así mismo, hizo hincapié en las dinámicas coercitivas a las que fueron sometidos los que recurrieron a los terapeutas y sospechados, posteriormente, que dijeron de más:

Absolutamente ninguno tiene el historial limpio y, si uno pisa el consultorio, los otros especulan de lo que se podría estar refiriendo, me imagino a lo relativo a los arreglos escabrosos de lo diario. No quieren que se cuente aquello que ocurre entre ellos, ya sea en las calles o en las comisarías. Al que cuenta le espera el escritorio o sentarse sin una función asignada. El código inviolable es no inferir sobre su labor a nadie (Entrevista n. ${ }^{\circ} 4$. Hospital de la ciudad de Asunción, 30/01/2020).

A su vez, las narraciones del Entrevistado n. ${ }^{\circ} 1$ ahondaron en los escarmientos. Los correctivos han sido una realidad innegable en las fuerzas $\mathrm{y}$, al que se atrevió a comentar lo indebido, le aguardaron diversas clases de penas:

Los castigos dependen del lugar en el que se está. En el interior del país, si se ve comprometido el jefe, al que delató se lo manda a Asunción para hacer tareas de ordenanza o se le aplica una sanción muy fuerte, una para que aprenda bien. En las ciudades en las cuales hay narcotráfico, se tiene la sospecha de amenazas contra el cuerpo y la vida de los policías. A los que se hallan en la capital, el freezer ${ }^{2}$, bien sentaditos sin hacer nada. También varía según aquello que se contó. No es lo mismo un caso de drogas que una queja por el atosigamiento de un compañero, ¿me estás entendiendo? (Entrevista n. ${ }^{\circ}$ 1. Comisaría de la ciudad de Asunción, 14/12/2019).

En este estadio deliberativo, se han determinado algunas conclusiones surgidas por lo sentenciado en los diversos expertos. Primero, el contexto de consulta, sin lugar a dudas, fue uno complicado para los oficiales interesados

${ }^{2}$ Término usado en la función pública paraguaya, uno que quiere decir: empleado castigado al que no le asignan funciones específicas. 
en ir al psicólogo, pero lo ha sido, primordialmente, por el chismerío dañino que provocaron los colegas al tener miedo de lo que se expuso en la terapia. Segundamente, la habladuría consistió en construir la figura del "compañero-paciente" como la de un sujeto inmerso en debilidades, unas traducidas en la no aptitud de ser un policía real. Y, terceramente, ese simbolismo de "blandura", sin embargo, no se debió a una cuestión del disparar o del saber morir o matar, significó la potencialidad de contar de más, de relatar las vicisitudes de la ocupación, muchas de ellas de dudosa legalidad, que pondrían en peligro los intereses y fines de los propios, los jefes o las autoridades civiles de la institución. En el punto, el Entrevistado n. ${ }^{\circ}$, comentaba:

Tenés que diferenciar lo que es hablar y contar. Hablar se basa en mencionar las dificultades personales por algún drama con sus hijos, padres, hermanos, novias o señoras. Después el contar, el que se entiende por lo que sucede dentro del oficio. Nunca cuentan, hablan. Se sientan y te dicen: "tengo un problema, no con mi trabajo, sino con mi esposa del que te deseo hablar". Asumieron que las sospechas abundan en los que asistieron al psicólogo y, de hecho, brotó el supuesto que si se acude es únicamente por la familia. Para el que se pasó el precepto, aparecieron un conjunto de sanciones, implícitas y explícitas, que lo señalaron en un delator (Entrevista n. ${ }^{\circ}$

3. Hospital de la ciudad de Asunción, 27/01/2020).

Que se haya establecido una oposición entre el "hablar" y el "contar", siendo uno permitido y otro denegado, ha reforzado la idea de una organización que se ha sabido mover en la lógica de pautas culturales demarcadas por el factor miedo: "miedo a asistir por el qué dirán", "miedo a lo que le estará comentando al terapeuta", "miedo al chisme", "miedo a la posible represalia por expresar de más". Ha primado una cultura del miedo en los oficiales, una que ha entablado un patrón de conducta, tanto en lo personal como en lo grupal, que ha dictaminado: "hablarás de lo tuyo, pero no contarás nada de lo nuestro". Por "lo tuyo" se constituyeron los problemas familiares y, por "lo nuestro", cuestiones al oficio de ser un agente de seguridad de lo público.

Bajo lo explicado en el párrafo anterior, efectivamente, se ha originado el "pacto confesional" entre el paciente y el experto. Se podrá preguntar, opinar y expresar de todo menos lo que haya sido el desempeño en las tareas. A pesar del secreto y la ética profesional, para los custodios no han importado dichas garantías y se fijaron, por lo tanto, que la confianza y el acercamiento con el 
psicólogo se daría por inconvenientes de tintes individuales, exclusivamente. $\mathrm{Al}$ respecto, los Entrevistados n. ${ }^{\circ} 3$ y 4 , afirmaban seguros:

El término correcto es obligación. Estoy rondando en el hospital por un buen tiempo y, te puedo asegurar, que casi de la totalidad de los policías que atendí, ninguno de ellos vino por una razón propia del trabajo. Somos el último recurso, cuando las cosas se volvieron insostenibles y apareció la amenaza de la señora o la novia, por ejemplo. "Si no te vas a arreglarte, no entras más a esta casa", te cuentan. Quieren decir cosas que únicamente tengan que ver con eso, si preguntas de más, ves que aparece una desconfianza y, hasta cierto punto, se muestran molestos (Entrevista n. ${ }^{\circ} 3$. Hospital de la ciudad de Asunción, 27/01/2020).

Confían en nosotros para arreglar los dramas que les van apareciendo en sus casas. Ahora bien, no te creas que somos su primera opción. Muchas veces son las propias señoras que se acercan y nos cuentan cosas de sus maridos para después generar una intervención. Nadie se enoja mientras no mencionemos cosas de su día a día. Somos un recurso, una última opción, cuando el hogar está por explotar. Para eso servimos y se entiende, si le indagamos sobre su contexto laboral pueden tener problemas y eso nadie quiere, más aún si no es el deseo del paciente (Entrevista n. ${ }^{\circ} 4$. Hospital de la ciudad de Asunción, 30/01/2020).

Obsérvese en este apartado debatido que los policías recurrieron a los psicólogos por la insistencia familiar. Los agentes, consecuentemente, se hallaron inmersos en dos clases de coacciones: la externa-institucional, una que les indicó no contar sobre el oficio; y b) una hogareña: la imperiosidad de hablar para solucionar sus problemas o el potencial quiebre del núcleo interno, uno que será inevitable, tarde o temprano, si no se hiciera nada en uno. Al respecto, la sistematización de lo hallado se pudo encontrar en la Tabla de Análisis n. ${ }^{\circ} 1$. 
Tabla n. ${ }^{\circ}$ 1: Dinámica de consulta psicológica del policía paraguayo

\begin{tabular}{|c|c|c|c|c|c|}
\hline Escenario & Dimensión & Sentimiento & Agentes & Factores & Dinámicas \\
\hline \multirow{2}{*}{$\begin{array}{l}\text { Consulta } \\
\text { psicológica } \\
\text { del policía }\end{array}$} & Externa & Miedo & Compañeros & $\begin{array}{l}\text { No existe } \\
\text { intimidad, } \\
\text { e impera } \\
\text { un temor al } \\
\text { qué dirán y } \\
\text { posteriores } \\
\text { represalias. }\end{array}$ & $\begin{array}{l}\text { Prohibido } \\
\text { "contar" } \\
\text { aspectos del } \\
\text { trabajo. }\end{array}$ \\
\hline & Interna & Obligatoriedad & Familiares & $\begin{array}{c}\text { Arreglar los } \\
\text { problemas } \\
\text { individuales } \\
\text { para } \\
\text { mantener } \\
\text { en pie las } \\
\text { relaciones } \\
\text { personales- } \\
\text { afectivas. }\end{array}$ & $\begin{array}{l}\text { Se puede } \\
\text { "hablar" } \\
\text { con plena } \\
\text { libertad de los } \\
\text { inconvenientes } \\
\text { familiares. }\end{array}$ \\
\hline
\end{tabular}

Elaboración propia, con base a las entrevistas realizadas.

\section{Los inconvenientes: problemas y el desarrollo de la consulta}

Decretado el "pacto confesional", uno bajo la premisa: "hablarás de ti, pero no contarás nada de tu trabajo", la investigación ha pasado a su segundo nivel de indagación, uno definido en los problemas concisos que han manifestado a los terapeutas. Si lo adecuado fue mencionar sobre sus contextos individuales, entonces: ¿qué tipo de inconvenientes surgieron en ese ámbito?, o dicho de una manera alterna: ¿qué han establecido como las dificultades familiares? Al respecto, el Entrevistado n. ${ }^{\circ} 3$ se refería:

A ellos les es muy difícil tener su vida ordenada. Los que se encuentran en las comisarías, no siempre poseen de un horario de entrada y salida fijo y eso les afectó, pues no se estabilizaron en una rutina. Si los escuchas con detenimiento, la impresión que te dan es que todo es un desastre, transcurren muy poco con sus hijos y les es imposible coordinar. Efectivamente que la poca presencia en sus casas les trajo graves conflictos con sus cuer- 
pos y sus seres queridos (Entrevista n. ${ }^{\circ} 3$. Hospital de la ciudad de Asunción, 27/01/2020).

Lo sentenciado con anterioridad, fue complejizado por el Entrevistado n. ${ }^{\circ} 1$. En este caso, gracias al testimonio traído ahora a colación, se ha profundizado en ese "caos familiar reinante en la existencia de los agentes", uno descripto y explicado, nuclearmente, por una percepción de falta de entendimiento, a través de la mirada de ellos, por parte de sus conocidos más cercanos:

Se sienten incomprendidos, muy estresados. Sus ratos con sus esposas y chicos son escasos, y creen que se están sacrificando en demasía. Llegan a sus domicilios, reciben reclamos y ahí saltan las disputas. Las riñas les han provocado una doble angustia, primeramente, se enfrentaron a una profesión altamente demandante $\mathrm{y}$, por otra, no hallaron una empatía que les ha permitido gozar de cierta contención. Te cuentan sus tragedias y verdaderamente han sido eso, una especie de drama latente. Parece que no alcanzaron a congeniar, o hacer un buen malabarismo, con sus diversas áreas, no tuvieron un punto de apoyo y es ahí donde se generó el desgaste emocional por el que vinieron a consultar (Entrevista n. $^{\circ} 1$. Comisaría de la ciudad de Asunción, 14/12/2019).

Si bien los pacientes no narraron sus oficios de una forma directa, fue una realidad innegable que las causas de muchos de sus obstáculos internos se produjeron por asuntos relativos al hecho de ser vigilantes. Una ocupación agobiante que ha estimulado un agotamiento particular, con implicancias obvias en sus hogares. Aquí se ha radicado la prima razón que fue el detonante de la visita al experto de la salud mental. Los mismos se refirieron a unas tareas sin tiempos demarcados, extremadamente exigidos, en el que no han logrado establecerse, esto, consecuentemente, ha consumido sus ambientes íntimos, no consiguiendo normalizarlos. El Entrevistado $\mathbf{n}^{\circ}$ 1, volvía a agregar:

Conviven con el crimen, uno expresado y materializado de todas las maneras y expresiones posibles. Si estás en un lugar así, obviamente que vas a necesitar un reposo para tu cabeza. Ese descanso no lo conocen, no hay paz y no lidian con el ser policías y miembros de una familia, con cada una de esas cosas, con sus respectivas responsabilidades y dinámicas (Entrevista n. ${ }^{\circ}$ 1. Comisaría de la ciudad de Asunción, 14/12/2019). 
Aunque ninguno de los interrogados, hasta el momento, ha detallado los contratiempos específicos, hicieron saber que los policías se apreciaron relegados, en una soledad e incomprensión constante, siendo aquellas tres, las dificultades iniciales que más han sentido cuando comenzaron a contar sobre lo que les aquejaba. Así, el Entrevistado n. ${ }^{\circ} 4$ aludía:

Los ciudadanos ven a los uniformados como unos seres incapaces o que ejecutan mal sus proezas, no entienden los entornos por los que atraviesan diariamente. Sentados en el sofá, tengo la sensación de que las cuestiones le han superado, se han vencido. No pueden dejar la placa ya que es el único ingreso que tienen y con sus parientes, luego, se van a rematar ya que no los perciben con la calidez demandada. Te das cuenta de que es, o parece, un camino cerrado, si te pones en la perspectiva de ellos, claro está (Entrevista n. ${ }^{\circ}$ 4. Hospital de la ciudad de Asunción, 30/01/2020).

El estrés, la soledad y la incomprensión, formaron parte del estado psíquico de los oficiales-pacientes; sin embargo, la expresión "rematar" ha llamado poderosamente la atención al investigador $\mathrm{y}$, al pedir una mayor explicación al respecto, el psicólogo relacionó los sobresaltos con los suyos por el consumo en exceso de bebidas alcohólicas, una ingesta descomunal con el fin de descargarse, y desahogarse por la situación sin salida en la cual estuvieron inmersos. Aquí, una vez más, ha emergido el factor del trabajo como un aliciente de conflictos internos:

Es algo obvio, no pueden lidiar con el ser policía y con lo primero que se manifiestan es con la cerveza. No te voy a decir que son alcohólicos, pero es una verdad, que beben. Eso hizo que hayan sido más propensos a reacciones desmedidas. La poca paciencia y estar desinhibidos y frustrados, es ahí la chispa perfecta para que se ocasionen los choques con sus señoras, novias, padres e hijos (Entrevista n. ${ }^{\circ}$ 4. Hospital de la ciudad de Asunción, $30 / 01 / 2020)$.

Apoyando lo descrito, varias han sido las crónicas periodísticas que han expuesto a los oficiales en incidentes, provocados por la ingesta exagerada de alcohol. Se trae a colación el suceso cometido el 13 de abril de 2020 por el suboficial primero Luis Miguel González Alvarenga que, en pleno servicio de sus funciones, impactó su rodado con otro vehículo que se encontraba frente a una bodega expendedora de tragos (Diario ABC Color, 2020b abril 14). Igualmente, el 28 de octubre de 2016, la Comandancia Nacional ha emitido una resolución en la que ha dado de baja a 40 agentes, dos de los cesados correspondieron a vigilantes que se extralimitaron, repetitivamente, 
a causa de un estado comprobado de borrachera (Diario La Nación, 2016 octubre 28). El Entrevistado n. ${ }^{\circ} 1$, comentaba seguro:

Aunque en un principio lo ven como algo normal, el tomar después les llama la atención y vienen a contarte que están abusando. Te dicen: "una vez que llego a casa me preocupa que no dejo de meterle al chupi", para después afirmar: "tengo miedo de perder a mi familia por eso". El tomar nunca viene solo ya que trae gritos, peleas más fáciles y el no freno a los impulsos. Estas situaciones generaron angustias y son ellos mismos los que vienen a contarte (Entrevista n. ${ }^{\circ}$ 1. Comisaría de la ciudad de Asunción, $14 / 12 / 2019)$.

Si bien el consumo desmedido de alcohol puede ser el resultado de un trabajo estresante, es una realidad que este ha sido definido como un potenciador de conflictos entre los oficiales y los miembros de sus familias. Al preguntar sobre los temas de discusión específicos, el Entrevistado n. ${ }^{\circ}$ 2, comentaba unos surgidos por el incumplimiento de sus deberes de fidelidad para con sus cónyuges, principalmente:

Vivimos en un país machista, parece que el hombre paraguayo se tiene que probar teniendo muchas novias. Los policías pasan por la misma dinámica, en el sentido que están llenos de chicas y reclamos de filiación de hijos que tuvieron con otras personas que no fueron sus parejas oficiales. La dificultad pasa cuando las amantes llaman a las casas y en un contexto donde uno está ebrio y la esposa enojada, con toda la razón del mundo, explotan las cosas y se dan situaciones de violencia física y verbal (Entrevista n. ${ }^{\circ} 2$. Comisaría de la ciudad de Asunción, 22/12/2019).

\section{A lo dicho, el Entrevistado n. ${ }^{\circ}$ 4, agregaba:}

No son celos, los tipos tienen segundas familias, hijos no reconocidos, están llenos de amenazas de juicios de filiación. ¿Cómo te vas a sentir si te enteras de que tu pareja tiene una segunda vida? ¿Te va a gustar? Cuando sus señoras les encaran, para ellos eso no está mal, tener una segunda vida, con otra chica, en sus cosmovisiones es reivindicar su condición de hombre, de macho. Les retan y la reacción es violenta. Te das cuenta de que el policía, muchas veces, es un agente de inseguridad (Entrevista n. ${ }^{\circ} 4$. Hospital de la ciudad de Asunción, 30/01/2020).

Si en el apartado anterior, emergió una cultura institucional radicada en el miedo entre los propios policías, uno enmarcado en el no contar sobre 
las cuestiones del oficio, en este caso ha brotado una pauta de masculinidad tóxica, que ha definido aciagamente al país. En el informe: Violencia contra las mujeres en Paraguay: Avances y Desafios, realizado por la ONU Mujeres, se ha ostentado que en lo que corresponde a la violencia padecida por las féminas adultas, el fundamental lugar ha sido en los hogares donde el agresor se ha constituido en sus cónyuges (Organización de las Naciones Unidas, 2016, p. 18). De las denuncias en el 2014 y en el 2015, de hecho, el atacante se configuró en el marido o novio: $38 \%$ y $37 \%$ respectivamente. Dicha lógica, en palabras del Entrevistado n..$^{\circ}$, también se ha exteriorizado en las dinámicas de los agentes, una mayormente agravada por la ingesta de bebidas, y la poca fluidez de diálogo en los hogares de los policías:

\begin{abstract}
¿Ahora si conseguís observar el caos de ellos? Es muy fácil que salte el fuego en sus hogares. Se portan mal, están frustrados, consumen abundante cerveza, en definitiva, pareciera que no tienen un orden, un compás que les guíe. Voy a ser un irresponsable si te afirmo que todos los policías son así, pero los que vienen acá, en un $85 \%$, te relatan las mismas historias, con los mismos escenarios y conflictos (Entrevista n. ${ }^{\circ} 3$. Hospital de la ciudad de Asunción, 27/01/2020).
\end{abstract}

El 28 de agosto de 2020 se ha viralizado, en las redes sociales y en los noticiarios como portales informativos de la internet, la agresión del suboficial primero Pablo Galli a su pareja (Diario Última Hora, 2020 agosto $28)$. En el video se ha observado a una mujer siendo agredida en plena vía pública. El vigilante discutió con su acompañante, para luego ella salir a la calle a solicitar auxilio. El individuo la persiguió hasta la vivienda de al lado y al alcanzarla, le arrastró del cabello con el fin de que vuelva. Igualmente, el 8 de junio de 2020, una mujer y su padre fueron golpeados físicamente por un policía en la ciudad de Lima, San Pedro, después de que el uniformado amenazara de muerte al progenitor (Diario Última Hora, 2020b junio 8). Ambas crónicas han sido dos breves ejemplos según lo cual la violencia ha existido en la realidad hogareña de los agentes.

Los problemas familiares, por los que se han consultado con los terapeutas, han sido graves. El gendarme paraguayo se ha ostentado en un estado psíquico frágil, uno manifestado en una vida personal desordenada, llenos de inconvenientes, con múltiples consecuencias negativas en sus allegados. Aquí, sin embargo, aparece el factor más preocupante, aquel radicado en no poder apreciar transformaciones reales en sus pacientes. El Entrevistado n. ${ }^{\circ}$ 2, solo por citar, afirmaba categóricamente: 
Te escuchan, te dicen que van a cambiar, pero regresan a lo mismo. El trabajo dignifica al hombre y lo debería hacer más humano. En este caso, su ambiente laboral es muy perverso. Si sumamos eso, y sus posteriores secuelas por sus hábitos desenfrenados, con pautas culturales machistas, es que terminan así y no pueden escaparse del ciclo de destrucción en el cual están (Entrevista n. ${ }^{\circ}$ 2. Comisaría de la ciudad de Asunción, 22/12/2019).

Así, se ha conseguido concluir que el servidor de la protección y el orden antes de erigirse en un modelo a seguir, ha brotado en un elemento de inseguridad y de precaución en los suyos (ver Tabla de Análisis n. ${ }^{\circ}$ 2). Es también un hecho, por lo relatado en el último experto referido, que no importó cuánto uno se haya rehusado a contar sobre la profesión, ella los afectó y, la mejoría auténtica, se ha establecido, consiguientemente, en una simple quimera.

Tabla n. ${ }^{\circ}$ 2: Dinámica de los inconvenientes relatados por la policía paraguaya

\begin{tabular}{|c|c|c|}
\hline $\begin{array}{c}\text { Sensaciones en el } \\
\text { momento de la consulta }\end{array}$ & $\begin{array}{c}\text { Estado } \\
\text { Psíquico }\end{array}$ & $\begin{array}{c}\text { Problemas } \\
\text { manifestados }\end{array}$ \\
\hline & Incomprensión & Alcoholismo \\
\cline { 2 - 3 } $\begin{array}{c}\text { Una existencia caótica, } \\
\text { sin salida aparente por un } \\
\text { desorden generalizado }\end{array}$ & Soledad & $\begin{array}{c}\text { Violencia hacia sus } \\
\text { parejas }\end{array}$ \\
\cline { 2 - 3 } & Estrés en & $\begin{array}{c}\text { Vida Familiar } \\
\text { general } \\
\text { constanten peleas } \\
\text { con sus parejas, } \\
\text { demandas por filiación } \\
\text { y conflictos con sus } \\
\text { amantes. }\end{array}$ \\
\hline
\end{tabular}

Elaboración propia, con base a las entrevistas realizadas.

\section{Principales conclusiones}

Por lo mencionado, desde los testimonios recogidos por los cuatro psicólogos, se pudo apreciar que las confesiones policiacas se situaron en los problemas familiares. La violencia, el alcoholismo y los inconvenientes extramatrimoniales fueron los tres sucesos que marcaron una relación 
conflictiva de los agentes para con los suyos, siendo estas las razones de consultas que los han llevado con los terapeutas.

Aunque varios de los especialistas en la salud mental, afirmaron que aquellos acudieron por una presión, una dictaminada en el terreno de las amenazas, por el miedo a perder sus familias, es una verdad que la atención se ha dado, que el policía ha decidido acudir al psicólogo y, ante ellos, confesar sus dramas en su núcleo interno con el fin de modificar la realidad en ese entorno. Las confesiones, antes de ser obligadas, fueron decisiones consientes y pensadas $\mathrm{y}$, por tal motivo, las mismas se produjeron en los dominios de las "tecnologías del yo" o "técnicas de sí", aquellas estipuladas por Michel Foucault.

La "técnica de si", sin embargo, fue una enlazada a una mejoría del ser en su rol de cabeza de familia, no en el policial. Del ejercicio de seguridad no se contó nada, se ha decretado tal norma, y, por esta razón, los esfuerzos siempre se radicaron en parciales y escasos. Así, y aunque hayan intentado arreglar sus vidas personales, toda iniciativa fue insuficiente, principalmente por la limitación antes dicha. Como lo estableció el último profesional indagado: el ambiente laboral es muy perverso (...) y no pueden escaparse del ciclo de destrucción en el cual están (Entrevista n. ${ }^{\circ}$ 2. Comisaría de la ciudad de Asunción, 22/12/2019).

Las entrevistas hechas, indirectamente, también exhibieron a una organización llena de prejuicios, sanciones implícitas y amedrentamientos a sus respectivos uniformados. A ello, el pacto confesional se dio restringido. El policía paraguayo, ha necesitado de una imperiosa contención, incluso, de un profundo cambio en sus formas y modos de relacionarse con los compañeros. Aquí, sin lugar a dudas, se orientaron las conclusiones al llamamiento urgente hacia la creación de una serie de políticas públicas, que pudieran revertir las coyunturas expuestas, tanto en los quehaceres y en los valores imperantes.

La Policía Nacional Paraguaya, no fue un grupo homogéneo que solo se ha dedicado a acatar órdenes. Esta ha gozado de una vivencia diaria; en definitiva, si ella resultara en una configuración adversa, jamás se podría llegar a obtener una entidad eficiente en su lucha contra las ilegalidades y la transgresión en general.

A las futuras investigaciones, ha quedado la tarea de seguir indagando en las dificultades surgidas durante el desarrollo de las actividades de protección. Estudiosos, con mayor habilidad, fuera de quien escribe el presente artículo, quizás consigan el acceso directo a los gendarmes y, por consiguiente, logran ampliar el análisis y poder complementar al texto ahora finalizado. 


\section{Referencias bibliográficas}

Diario ABC Color. (2020, julio 3). Alrededor de 3000 efectivos presentan indicios de trastornos psicológicos cuando buscan ascender. En ABC Color. https://www. abc.com.py/nacionales/2020/07/03/alrededor-de-3000-efectivos-presentanindicios-de-trastornos-psicologicos-cuando-buscan-ascender/

Diario ABC Color. (2020b, abril 14). Fiscala imputa a policía ebrio solo por violar la cuarentena. En $A B C$ Color. https://www.abc.com.py/edicion-impresa/ judiciales-y-policiales/2020/04/14/fiscala-imputa-a-policia-ebrio-solo-porviolar-la-cuarentena/

Diario ABC Color. (2020c, julio 3). Recomiendan test psicológico a uniformados al menos una vez al año. En $A B C$ Color. https://www.abc.com.py/ nacionales/2020/07/03/recomiendan-test-psicologico-a-uniformados-al-menosuna-vez-al-ano/

Diario ABC Color. (2021, enero 25). Trama de ajusticiamientos en filas policiales se devela tras detención de "polisicario". En ABC Color. https://www.abc.com.py/ nacionales/2021/01/25/trama-de-ajusticiamientos-en-filas-policiales-se-develatras-detencion-de-polisicario/

Agamben, G. (2011). ¿Qué es un dispositivo? Sociológica, 26(73), 249-264.

Castro, E. (2019). La noción de policía en los trabajos de Michel Foucault: objeto, límites, antinomias. Anuario Colombiano de Historia Social y de la Cultura, 46(2), 185-206. https://doi.org/10.15446/achsc.v46n2.78218

Castro-Gómez, S. (2007). Michel Foucault y la colonialidad del poder. Tabula Rasa, Revista de Humanidades, (6), 153-172.

Foucault, M. (2003). Hay que defender la sociedad. Ediciones Akal.

Foucault, M. (2008). Seguridad, territorio y población. Fondo de Cultura Económica. Foucault, M. (2008b) Nacimiento de la Biopolítica. Fondo de Cultura Económica. Foucault, M. (2008c). La ética del pensamiento. Obra.

Foucault, M. (2011). La voluntad de saber. Siglo XXI.

Foucault, M. (2012). El poder, una bestia magnifica. Siglo XXI Editores.

Foucault, M. (2014). Obrar mal, decir la verdad. Siglo XXI.

Garcia Fanlo, L. (2011). Que es un Dispositivo, por Foucault, Deleuze y Agamben. A Parte Rey, (74), 1-8.

Diario La Nación. (2016, octubre 28). Irán de baja 40 policías y pasarían a retiro 234. En La Nación. https://www.lanacion.com.py/2016/10/29/iran-baja-40policias-pasarian-retiro-234/

Diario La Nación. (2019, septiembre 24). PGN: Preocupa falta de recursos para la Policía y poco interés del Gobierno. En La Nación. https://www.lanacion.com. py/politica/2019/09/24/pgn-preocupa-falta-de-recursos-para-la-policia-y-pocointeres-del-gobierno/

Diario La Nación. (2020, julio 3). Policía que mató a su familia ya contaba con una denuncia por violencia doméstica. En La Nación. https://www.lanacion.com.py/ pais/2020/07/03/policia-que-mato-a-su-familia-ya-contaba-con-una-denunciapor-violencia-domestica/ 
Meza, Á. (2010). Código de Ética de la Policía Nacional del Paraguay. Policía Nacional, Asunción.

Moriconi, M. (2013) Ser violento. Los origenes de la inseguridad y la víctimacómplice. Capital Intelectual.

Organización de las Naciones Unidas (2016). Violencia contra las mujeres en Paraguay: Avances y Desafios. ONU Mujeres, Asunción.

Romero, F. (2017). La confesión en los juegos de verdad, la relación saber-poder y la subjetividad en la filosofia de Michel Foucault. Universidad de Puebla.

Torrano, Andrea. (2016). Las políticas de visado en el dispositivo de seguridad de Michel Foucault. En-claves del pensamiento, 10(20), 79-96.

Diario Última Hora. (2020, agosto 28). Buscan al policía que arrastró del cabello a su esposa. En Última Hora. https://www.ultimahora.com/buscan-al-policiaque-arrastro-del-cabello-su-esposa-n2902095.html

Diario Última Hora. (2020b, junio 8). Graban agresión de policías en puesto de control en San Pedro. En Última Hora. https://www.ultimahora.com/grabanagresion-policias-puesto-control-san-pedro-n2889195.html

Valencia, D. (2014). La lógica de lo social y el arte de gobernar en Foucault: una caja de herramientas para el análisis político. Praxis Filosófica, (39), 111-133. https://doi.org/10.25100/pfilosofica.v0i39.3517

204 Vélez Vega, J. (2016). El medio y el dispositivo de seguridad: consideración desde el pensar foucaultiano. HYBRIS. Revista de Filosofia, 7(1), 109-128. http:// dx.doi.org/10.5281/zenodo.51655 